\title{
Analysis of the Accuracy about Abdominal Ultrasonography and Clinical Chemical Test with Fatty Liver Patients on the Medical Examination
}

\author{
Youngjae Kim*, Jongnam Song*, Mineui Kim ${ }^{* *}$ \\ Dept. of Radiation Technology, Gwangyang Health College*, \\ Dept. of Laboratory Medicine, Seoul St. Mary's Hospital, Catholic University of Korea**

\section{종합검진 후 지방간 환자의 복부 초음파 검사와 임상화학적 검사결과의 정확성 분석}

\author{
김영재*, 송종남*, 김민의** \\ 광양보건대학교 방사선과*, 가톨릭대학교 서울성모병원 진단검사의학과**
}

\begin{abstract}
Ultrasonography is one of the fields on the imaging studies within intra-abdominal organs. A blood test is a typical method of clinical chemical examination on the in vivo test of clinical symptoms. Fatty liver is performed simultaneously two kinds of diagnostics methods, intra-abdominal ultrasound and blood tests. At an implementing this, the standard of blood tests value was the TBIL, TC, AST, ALT, ALP, GGT, TG, HDL-C, GLU. In this study analyzing the accuracy of the two kinds of test, ultrasonography and blood test, on patients with fatty liver. From January to March 2012, patients 459 determined fatty liver within 1350, who received health examination simultaneously on the intra-abdominal ultrasonography and blood tests. Same result of ultrasonography and blood test's patients were $459 \mathrm{ie}, 60.8 \%$. and different result of those examinations was 280 ie, $39.2 \%$. Consequently diagnostic accuracy was $60.8 \%$. It presumably caused by differences in the diagnostic performance of ultrasound professionals(Radiologist or Radiological Technologist). In order to overcome this, ongoing educational and study will be needed
\end{abstract}

Key Words : Ultrasonography, Blood test, Accuracy of inspections

\section{요약}

초음파 검사는 복강내 장기를 검사하는 대표적인 영상의학검사의 한 분야이며. 혈액검사는 체내 이상 징후를 임상 화학적으로 검사하는 대표적인 방법이다. 지방간의 진단은 주로 복부초음파 검사와 혈액검사를 동시에 실시하여 수행 하며 두 검사의 결과를 바탕으로 진단을 하게 된다. 이 경우에 실시하는 혈액검사의 기준은 TBIL, TC, AST, ALT, $\mathrm{ALP}, \mathrm{GGT}, \mathrm{TG}, \mathrm{HDL}-\mathrm{C}, \mathrm{GLU}$ 의 값이다. 본 연구에서는 초음파 영상에서 지방간 진단을 받은 환자의 혈액검사 정확 성을 분석하여 두 종류의 검사간 정확도를 분석하고자 하였다. 2012년 1월부터 3월간 종합검진으로 복부초음파검사와 
혈액검사를 동시에 받은 환자 1350 명 중 초음파 검사 상 지방간 판정을 받은 459 명을 대상으로 초음파 검사와 혈액검 사 결과가 동일한 경우는 459 명 중 280 명으로 약 $60.8 \%$ 이며, 초음파 검사와 혈액검사의 결과가 서로 다른 경우는 179 명으로 $39.2 \%$ 로 밝혀져 초음파 검사와 혈액검사의 진단 정확도는 $60.8 \%$ 이었다. 이는 지방간의 초음파 진단시 종 사자의 주관적 능력이 병변의 진단에 큰 영향을 미친 것으로 생각되어 지속적인 초음파 임상 교육이 필요할 것으로 사 료된다.

중심단어: 초음파, 혈액검사, 검사간 정확성

\section{I. 서 론}

초음파 검사는 복강 내 장기 즉, 간, 담낭, 비장, 신 장, 췌장, 자궁, 방광 등을 관찰 할 수 있는 검사법이 다. 이 중 간질환의 진단에는 병력, 이학적 소견, 혈액 검사, 초음파 검사가 이용되고 특히, 지방간, 낭종, 담 석의 진단을 위해서는 $\mathrm{CT}$ (Computed Tomography)검사 소견이 도움이 되지만 결과적으로는 간생검으로 확진 된다 ${ }^{[1]}$ 하지만 임상에서 간생검을 실시 하고자 하면 환자들의 거부사례가 많아 현재에는 생검보다 초음파 검사나 CT검사를 많이 이용하고 있다 ${ }^{[2]}$. 또한 초음파 방법 이외에 간질환을 알아보기 위한 방법으로 임상 화학적 검사 즉, 혈액을 얻어 검사하는 방법이 있는데 이 검사법의 종류는 Total bilirubin(TBIL), Total cholesterol(TC), Aspartate aminotransferase(AST), Alanine aminotransferase(ALT), Alkaline phosphatase (ALP), 8 -Glutamyl transferase(GGT), Triglyceride (TG), High density lipoprotein-cholesterol(HDL-C), Glucose(GLU)이 있다. 초음파 검사와 임상화학적 검사는 경제적이며 간편하고 손쉽게 혈액을 얻을 수 있는 장점이 있기 때 문에 간질환의 진단을 위하여 초음파 검사와 혈액검 사를 병행하고 있다.

이에 본 논문은 지방간을 초기에 발견해 내는데 있 어 일반인들이 부담을 느끼지 않는 초음파 검사와 간 단한 임상화학적인 검사결과를 통하여 환자의 양방향 검사의 상호 연관관계와 정확도를 알아보고자 한다.

\section{II. 연구대상 및 방법}

\section{1. 연구대상}

연구대상은 2012년 1월에서 3월까지 서울의 S대학 병원에서 종합검진으로 복부초음파와 임상화학검사검
사를 동시에 실시 받은 1350 명을 대상으로 하였으며, 이 중 지방간으로 확정 판정을 받은 459 명을 대상으로 하였다.

\section{2. 연구방법}

검사 대상자 모두는 NPO 6시간 이상을 유지한 상 태에서 초음파 진단장치(Acuson S2000, Siemens, Germany)를 이용하여 복부초음파 검사를 실시하였으 며, 동시에 혈액검사도 실시하였다. 혈액검사는 진단 검사의학과에서 1 시간 이내 혈청을 분리하여 TBIL, TC, AST, ALT, ALP, GGT, TG, HDL-C, GLU 등을 가 검물 자동화 분석기(Hitachi7600-210, jw-medical, Japan) 를 이용하여 분석 하였다.

초음파결과 정상 환자로 판정된 경우 혈액검사결과 를 분석하여 초음파 검사와 혈액검사의 일치성을 분 석하였고, 초음파상 지방간 환자로 판정된 경우 초기, 중등도, 고도의 지방간으로 분류하여 혈액검사와 일치 성을 분석하여 초음파 검사와 혈액검사의 지방간 분 석 정확도를 측정하였다.

자료수집 후 분석은 $\mathrm{SAS}($ Statistic Analysis System)을 이용하여 전체 환자 1350 명 중 지방간을 초기, 중등도, 고도의 지방간으로 분류한 결과 각각 213 명, 159 명, 87 명이었으며 이 환자들의 혈액검사 결과와 초음파 검 사결과, 그리고 실제 진단의 정확성 분석하였고 $\mathrm{p}$ 값이 0.05 미만인 경우 유의한 차이가 있는 것으로 하였다.

\section{III. 결 과}

\section{1. 조사대상자의 분류}

조사 대상자는 총 1350 명이었으며 대상자의 성별은 남성이 690명이었으며 여성은 660 명으로 연령대는 10 대와 70 대가 가장 적었고, 40 대와 50 대가 가장 많았 
다.(Table 1)

Table 1. General characteristics of subjects

\begin{tabular}{cccc}
\hline Age & Male(\%) & Female(\%) & Total (\%) \\
\hline $10-19$ & $6(0.8)$ & $3(0.5)$ & $9(0.7)$ \\
$20-29$ & $33(4.8)$ & $24(3.6)$ & $57(4.2)$ \\
$30-39$ & $177(25.7)$ & $96(14.5)$ & $273(20.2)$ \\
$40-49$ & $213(30.9)$ & $177(26.8)$ & $390(28.9)$ \\
$50-59$ & $165(23.9)$ & $234(35.5)$ & $399(29.6)$ \\
$60-69$ & $69(10)$ & $111(16.8)$ & $180(13.3)$ \\
70 이상 & $27(3.9)$ & $15(2.3)$ & $42(3.1)$ \\
\hline Total & $690(100)$ & $660(100)$ & $1350(100)$ \\
\hline
\end{tabular}

\section{2. 조사대상자의 초음파 소견}

조사대상자의 초음파 소견으로는 정상이 690 명 (55.6\%)으로 가장 많았으며 지방간은 459 명 $(34 \%)$ 으로 그 중 경미한 지방간이 213명(15.8\%)으로 가장 많았고 진행성 지방간이 159 명 $(11.8 \%)$, 중증도 지방간이 87 명 (6.4\%)으로 나타났다. 그 밖에 간성 낭종은 93 명 $(6.9 \%)$ 으로 나타났으며 담석증과 간흡충증은 각각 30 명 $(2.2 \%), 18$ 명(1.3\%)로 집계되었다(Table 2).

Table 2. Ultrasonographic findings

\begin{tabular}{|c|c|c|c|c|}
\hline & & Male $(\%)$ & Female (\%) & Total $(\%)$ \\
\hline \multicolumn{2}{|c|}{ Normal } & $357(51.7)$ & $393(59.4)$ & 750 (55.6) \\
\hline \multirow{3}{*}{$\begin{array}{l}\text { Fatty } \\
\text { liver }\end{array}$} & mild & $120(17.4)$ & $93(14.1)$ & $213(15.8)$ \\
\hline & moderate & $84(12.2)$ & $75(11.4)$ & $159(11.8)$ \\
\hline & severe & $45(6.5)$ & $42(6.4)$ & $87(6.4)$ \\
\hline \multicolumn{2}{|c|}{ Hepat ic cyst } & $60(8.7)$ & $33(5.0)$ & $93(6.9)$ \\
\hline \multicolumn{2}{|c|}{ GB stone } & $15(2.2)$ & $15(2.3)$ & $30(2.2)$ \\
\hline \multicolumn{2}{|c|}{ Clonorchiasis } & $9(1.3)$ & $9(1.4)$ & $18(1.3)$ \\
\hline \multicolumn{2}{|c|}{ Total } & $690(100)$ & $660(100)$ & $1350(100)$ \\
\hline
\end{tabular}

\section{3. 임상화학적 검사의 결과값}

검사대상자 전체 즉, 정상소견과 비정상소견을 모두 포함하여 혈액을 검사한 결과값은 Table 2와 같다.

Table 4. The results of chemical analysis in the blood

\begin{tabular}{cccc}
\hline & Mean \pm SD & Minimum & Maximum \\
\hline TBIL & $0.8 \pm 0.3$ & 0.5 & 8.4 \\
TC & $190.7 \pm 36.4$ & 73.8 & 335.7 \\
AST & $26.9 \pm 16.5$ & 12.8 & 224.1 \\
ALT & $27.9 \pm 23.9$ & 6.5 & 245.9 \\
ALP & $180.3 \pm 67.8$ & 50.3 & 1129.4 \\
GGT & $34.5 \pm 40.8$ & 6.5 & 488.2 \\
TG & $132.4 \pm 89.7$ & 21.7 & 635.1 \\
HDL-C & $49.4 \pm 13.7$ & 10.5 & 101.9 \\
GLU & $95.4 \pm 29.3$ & 60.2 & 342.7 \\
\hline
\end{tabular}

\section{4. 초음파 검사상 정상 판정 받은 대상자의 혈액 검사 결과값}

초음파 검사 대상자 중 정상 판정을 받은 대상자의 혈액 검사의 결과 값은 Table 5 와 같다.

Table 5. The results of chemical analysis in the blood from normal subjects by ultrasonography

\begin{tabular}{cccc}
\hline & Mean \pm SD & Min & Max \\
\hline TBIL & $0.95 \pm 0.7$ & 0.3 & 8.8 \\
TC & $186.1 \pm 33.5$ & 73.5 & 305.1 \\
AST & $24.3 \pm 13.5$ & 12.7 & 195.5 \\
ALT & $23.8 \pm 17.8$ & 6.3 & 192.5 \\
ALP & $173.8 \pm 65.2$ & 48.7 & 812.4 \\
GGT & $27.3 \pm 32.8$ & 7.4 & 424.7 \\
TG & $109.7 \pm 65.7$ & 23.1 & 578.7 \\
HDL-C & $51.8 \pm 12.7$ & 4.6 & 101.1 \\
GLU & $91.9 \pm 25.4$ & 58.8 & 340.4 \\
\hline
\end{tabular}




\section{5. 초음파 검사상 지방간 진단을 받은 대상자의 혈 액 검사 결과}

초음파 검사 대상자 중 지방간(초기, 중등도, 고도) 진단을 받은 대상자의 혈액 검사의 결과 값은 Table 6 과 같으며 초음파 영상에서 지방간의 악성진단에 대 한 영상은 Fig 1 과 같으며 지방간의 심각도를 기준으 로 상호 비교한 결과는 $\mathrm{Fig} 2$ 와 같다.

Table 6. The results of chemical analysis in the blood from the patients with fatty liver by ultrasonography (unit: Mean \pm SD)

\begin{tabular}{|c|c|c|c|}
\hline & $\begin{array}{c}\text { Mild (Mean } \pm \\
\text { SD) }\end{array}$ & $\begin{array}{l}\text { Moderate (Mean } \pm \\
\text { SD) }\end{array}$ & $\begin{array}{c}\text { Severe (Mean } \pm \\
\text { SD) }\end{array}$ \\
\hline TBIL & $0.9 \pm 0.4$ & $0.9 \pm 0.5$ & $0.9 \pm 0.4$ \\
\hline$T C \star \star$ & $196.8 \pm 29.5$ & $210.1 \pm 34.7$ & $218.1 \pm 39.8$ \\
\hline AST & $27.6 \pm 20.6$ & $30.1 \pm 11.5$ & $36.1 \pm 16.8$ \\
\hline 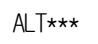 & $30.7 \pm 25.4$ & $39.5 \pm 23.1$ & $53.5 \pm 32.2$ \\
\hline$A L P *$ & $183.4 \pm 53.5$ & $190.5 \pm 51.8$ & $212.5 \pm 49.5$ \\
\hline GGT** & $40.2 \pm 37.8$ & $41.3 \pm 29.9$ & $72.4 \pm 90.1$ \\
\hline 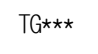 & $142.9 \pm 73.4$ & $210.6 \pm 140.5$ & $227.6 \pm 129.1$ \\
\hline$H D L-C * *$ & $51.1 \pm 11.9$ & $46.2 \pm 8.1$ & $42.6 \pm 10.6$ \\
\hline GLU* & $98.5 \pm 26.4$ & $102.4 \pm 28.5$ & $116.4 \pm 44.2$ \\
\hline
\end{tabular}

$\star: p<0.05, \star \star: p<0.01, * \star \star: p<0.001$

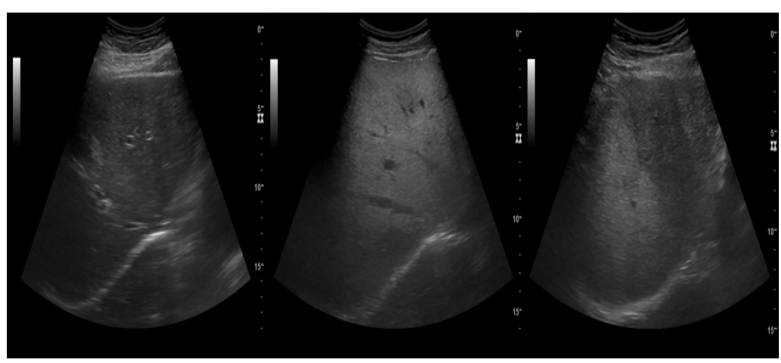

Mild Moderate Servere

Fig 1. Classified ultrasonography based on the severity of fatty liver.

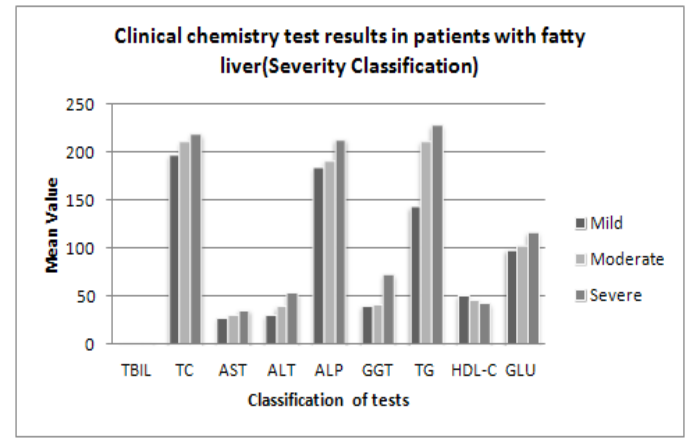

Fig 2. Clinical chemistry test results in patients with fatty liver(Severity Classification)

6. 초음파 검사에서 정상소견을 보인 경우와 지방 간이 있는 경우의 혈액검사의 관련성

초음파 검사 결과 정상소견과 지방간 소견을 보인 혈액검사 결과 TC에서 각각 $184.9 \pm 33.9,204.1 \pm 34.9$ 로 $(\mathrm{p}<0.001)$ 나타났으며 ASP값은 각각 $25.2 \pm 15.0,30.1$ \pm 18.1 로 $(\mathrm{p}<0.01)$ 나타났다. ALT는 $24.1 \pm 18.2,37.2 \pm$ 27.1로 $(\mathrm{p}<0.001) \mathrm{TC}$ 값과 ASP값, 그리고 ALT값이 지방 간 소견을 보인 환자에게서 높게 나타났다. 특히 $\mathrm{TG}$ 값은 각각 $109.6 \pm 67.1,176.2 \pm 112.1$ 로 가장 큰 평균 값의 차이를 나타냈다. 하지만 HDL-C값의 경우 정상 소견과 지방간 소견의 수치가 $53.1 \pm 12.7,47.7 \pm$ $11.0(\mathrm{p}<0.001)$ 으로 지방간 소견일 경우가 다소 낮게 나 타났다(Table 7).

Table 7. Comparison of the results of chemical analysis in the blood from normal subjects and patients with fatty liver by ultrasonography

\begin{tabular}{|c|c|c|}
\hline & Normal (Mean \pm SD) & Fatty liver (Mean \pm SD) \\
\hline TBIL & $0.9 \pm 0.6$ & $0.9 \pm 0.4$ \\
\hline 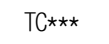 & $184.9 \pm 33.9$ & $204.1 \pm 34.9$ \\
\hline AST** & $25.2 \pm 15.0$ & $30.1 \pm 18.1$ \\
\hline 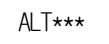 & $24.1 \pm 18.2$ & $37.2 \pm 27.1$ \\
\hline 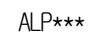 & $173.8 \pm 64.9$ & $189.4 \pm 54.0$ \\
\hline 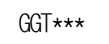 & $27.5 \pm 33.6$ & $44.0 \pm 48.7$ \\
\hline 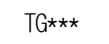 & $109.6 \pm 67.1$ & $176.2 \pm 112.1$ \\
\hline 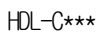 & $53.1 \pm 12.7$ & $47.7 \pm 11.0$ \\
\hline GLU** & $92.4 \pm 27.1$ & $102.1 \pm 32.6$ \\
\hline
\end{tabular}




\section{7. 초음파 검사결과와 혈액 검사 결과의 비교}

초음파 검사상 지방간의 정도에 따른 $\mathrm{TC}, \mathrm{ALT}$, ALP, GGT, HDL-C, GLU 등의 혈액 검사결과 상관성 이 있는 것으로 나타났고, 혈액 즉, 혈액검사상 지방간 임에도 불구하고 초음파상에 정상인 경우는 AST 4.8\%, ALT 4.6\%, TC 18.9\%, GGT 2.9\%, TG 2.7\%로 나 타났다. 혈액검사상 정상인데 반하여 초음파상 지방간 으로 보인 경우는 AST $35.8 \%$, ALT 29.8\%, TC 20.9\%, GGT 38.5\%, TG 37.1\%로 나타났다(Table 8).

Table 8. Comparison of the results of ultrasonography and chemical analysis in the blood

\begin{tabular}{|c|c|c|c|c|}
\hline & & \multicolumn{2}{|c|}{ UI trasonogr aphy } & \multirow{2}{*}{ Total } \\
\hline & & Normal & Abnormal & \\
\hline \multirow{2}{*}{ 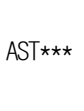 } & Normal & २2८ (50.8) & $161(35.8)$ & $389(86.6)$ \\
\hline & Abnormal & $22(4.8)$ & $39(8.6)$ & $61(13.4)$ \\
\hline \multirow{2}{*}{ 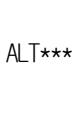 } & Normal & २२९ (50.9) & $134(29.8)$ & $363(80.7)$ \\
\hline & Abnormal & $21(4.6)$ & $66(14.7)$ & $87(19.3)$ \\
\hline \multirow{2}{*}{ ALP } & Normal & $235(52.2)$ & $187(41.6)$ & $422(93.8)$ \\
\hline & Abnormal & $15(3.3)$ & $13(2.9)$ & $28(6.2)$ \\
\hline \multirow{2}{*}{ TBIL } & Normal & $217(48.2)$ & $158(35.1)$ & $375(83.3)$ \\
\hline & Abnormal & $33(7.3)$ & $42(9.4)$ & $75(16.7)$ \\
\hline \multirow{2}{*}{$T C \star \star \star$} & Normal & $165(36.7)$ & $94(20.9)$ & $259(57.6)$ \\
\hline & Abnormal & $85(18.9)$ & $106(23.6)$ & $191(42.5)$ \\
\hline \multirow{2}{*}{ GGT** } & Normal & $237(52.7)$ & $173(38.5)$ & $410(91.1)$ \\
\hline & Abnormal & $13(2.9)$ & $27(6.0)$ & $40(8.9)$ \\
\hline \multirow{2}{*}{$H D L-C$} & Normal & $244(54.2)$ & $183(40.7)$ & 427 (94.9) \\
\hline & Abnormal & $6(1.3)$ & $17(3.8)$ & $23(5.1)$ \\
\hline \multirow{2}{*}{$T G \star \star$} & Normal & 238 (52.9) & $167(37.1)$ & $405(90.0)$ \\
\hline & Abnormal & $12(2.7)$ & $33(7.3)$ & $45(10.0)$ \\
\hline \multicolumn{2}{|c|}{ Total } & $250(55.6)$ & $200(44.4)$ & $450(100)$ \\
\hline
\end{tabular}

\section{8. 초음파 검사와 혈액 검사 결과의 정확도 평가}

Table 9. The accuracy of ultrasonography and blood samples inspection.

\begin{tabular}{|c|c|c|c|c|c|c|}
\hline & & \multicolumn{2}{|c|}{ UI trasonogr aphy } & \multirow{2}{*}{$\begin{array}{c}\text { Total } \\
\text { (C) }\end{array}$} & \multirow{2}{*}{$\begin{array}{l}\text { Match } \\
\text { Rat io } \\
(\mathrm{A} / \mathrm{C})\end{array}$} & \multirow{2}{*}{$\begin{array}{c}\text { Mismatc } \\
\text { h Rat io } \\
(\mathrm{B} / \mathrm{C})\end{array}$} \\
\hline & & $\begin{array}{l}\text { Match } \\
\text { (A) }\end{array}$ & $\begin{array}{l}\text { Mismat } \\
\text { ch (B) }\end{array}$ & & & \\
\hline \multirow{5}{*}{$\begin{array}{l}\text { Blood } \\
\text { Inspe } \\
\text { ction }\end{array}$} & ASP & 267 & 183 & \multirow{5}{*}{450} & $59.3 \%$ & $40.7 \%$ \\
\hline & ALT & 295 & 155 & & $65.6 \%$ & $34.4 \%$ \\
\hline & TC & 271 & 179 & & $60.2 \%$ & $39.8 \%$ \\
\hline & GGT & 264 & 186 & & $58.7 \%$ & $41.3 \%$ \\
\hline & TG & 271 & 179 & & $60.2 \%$ & $39.8 \%$ \\
\hline \multicolumn{5}{|c|}{ Mean Value } & $60.8 \%$ & $39.2 \%$ \\
\hline
\end{tabular}

Table 8 에 있는 검체검사 결과 중에 통계적으로 유 의한 값을 보인 AST, ALT, TC, GGT, TG의 값을 이용 하여 초음파 검사와 혈액 검사 모두 정상소견을 보인 것과 모두 비정상소견을 보인 것을 비교해 본 결과 $\mathrm{ASP}$ 의 경우 $59.3 \%, \mathrm{ALT}$ 는 $65.6 \%$, TC와 GGT 그리고 $\mathrm{TG}$ 의 경우는 각각 $60.2 \%, 58.7 \%, 60.2 \%$ 의 값을 보여 평균 검사결과의 정확도의 비율은 $60.8 \%$ 이었으며 부 정확도의 비율은 $\mathrm{ASP}$ 의 경우 $59.3 \%$, ALT는 $65.6 \%$, TC 와 $\mathrm{GGT}$ 그리고 $\mathrm{TG}$ 의 경우는 각각 $60.2 \%, 58.7 \%$, $60.2 \%$ 의 값을 보여 평균 부정확도의 비율은 $39.2 \%$ 로 나타났다(Table 9).

\section{IV. 고찰 및 결론}

지방간은 간질환의 종류 중 하나로 정상적으로는 없어야 할 $\mathrm{TG}$ (트리글리세라이드, 중성지방)이 간에 전 반적으로 침착하여 간의 경도 내지는 중등도 이상의 소견을 보이는 일반적인 임상 및 병리적 소견으로 간 조직에 간중량의 $5 \%$ 이상 축적된 것을 말한다. ${ }^{[3],[4]}$ Lombadi 등은 지방간의 발생기전은 중성지방의 합성 과 이용 사이에 불균형이 있을 때 발생한다고 하였다. 즉, 간에서 중성지방의 이용 장애나 중성지방 합성의 증가, 합성의 증가에 대비한 중성지방의 체내 이용의 
감소, 중성지방이 소포체(Endoplasmic reticulum) 이외의 다른 세포질에서 합성될 경우 등이며, 이들 네가지 상 태 중 한가지에 장애가 있을 때 유발된다고 보고하고 있다 ${ }^{[5]}$.

Alder $\mathrm{M}$ 등 ${ }^{[6]}$ 이 조사한 연구에서 지방간은 그 유발 인자에 따라서 임상적 소견이 다른데 즉, 비만에 의한 지방산은 서서히 진행되어 간경변까지도 발전할 수 있다고 하였으며 Bode JC 등그은 알콜섭취로 인한 지 방간은 금주에 의해 3 6주 사이에 회복되는 경우도 있다고 주장하였다. 문성수 등 ${ }^{[8]}$ 은 간조직의 지방변성 은 때로 말단 간세정맥(terminal hepatic venule) 주변에 서 섬유화가 일어난다고 주장하였고, 지방간의 증상은 지방의 침착정도에 따라 달라진다고 하였으며 비만, 혹은 당뇨병으로 발생한 지방간은 대부분 증상이 없 으며, 우상복부 불편감, 식욕부진이 있다고 하였고 ${ }^{[9]}$, 전신피로감이 주증상이라는 보고도 있다 ${ }^{[10]}$.

초음파 검사에서 지방간을 보이는 주요한 소견으로 는 간 실질에코의 증가, 음향감쇠의 증가, 간 내 혈관 의 경계와 횡격막의 관찰이 어렵다는 것인다. 이진성 등 $^{[11]}$ 은 이와 같은 소견들은 점수화 하여 Grade I, I, III 등으로 나누어서 지방간의 정도를 판정하였으며 초음파의 검사소견과 $\mathrm{AST}$ 와 $\mathrm{ALT}$ 의 수치도 함께 연관 되었다는 보고를 하기도 하였다. 전경녀 등[1]은 직접 빌리루빈, GGT TG, AST, ALT는 초음파 상의 등급에 관계없이 평균값이 증가해 있어 초음파 상 지방간의 이상(Abnomal)을 시사할 수는 있다고 생각되나 미만성 지방간의 초음파 등급과 직접적인 연관성은 보이지 않았다고 하였으며, ALT만이 경증과 중증군 간에 의 미 있는 차이를 보였다고 하였다. 또한 초음파 검사상 경증의 지방간 소견을 보인 경우 중 $1 / 3$ 이상에서 생화 학적 간 기능 검사의 지표가 모두 정상범위에 있었는 데 이는 경도의 지방간은 간 기능의 이상을 잘 초래하 지 않거나 초음파 상에 위양성의 소견을 보여서 초래 된 것으로 생각된다고 하였다.

생검으로 지방간의 병변이 확진된 환자와 초음파 영상의 관계에 대한 문헌을 살펴보면 영상의학과 전 문의가 생검을 통하여 지방간 확진을 받았음에도 불 구하고 초음파 영상판독결과는 16 명을 지방간으로 진 단하고 4 명을 정상으로 판정하였다 ${ }^{[12]}$. 이는 초음파 영 상을 얻을 때 영상의학과 전문의의 주관적 소견과 임
상적 경험을 토대로 이뤄지기 때문인 것으로 파악된 다. 때문에 본 연구는 이러한 초음파의 한계를 극복하 고, 임상화학적 검사가 필요하다는 점을 피력하며, 동 시에 초음파 검사와 임상화학적 검사간의 정확도를 동시에 연구하려고 하였다.

본 연구에서는 지방간이 나타나는 비율이 1350 명 중 459 명 $(34 \%)$ 으로 전경녀 등 ${ }^{[1]}$ 이 연구한 결과보다 다소 높게 나타났으며 지방간의 경·중증도에 따라서 $\mathrm{TC}, \mathrm{AST}, \mathrm{ALT}, \mathrm{ALP}, \mathrm{GGT}, \mathrm{TG}, \mathrm{GLU}$ 검사에서 증가 추세를 보였으며 HDL-C에서는 감소추세를 보여 초음 파 검사와 임상화학적 검사간의 상관성이 있는 것으 로 나타났다.(Table 7) 그리고 혈액검사상 정상범위를 벗어났음에도 불구하고 초음파상 정상 $(\mathrm{Nomal})$ 으로 나 타난 비율은 AST $4.8 \%$, ALT 4.6\%, TC 18.9\%, GGT $2.9 \%, \mathrm{TG} 2.7 \%$ 이고 그 반대의 경우 즉, 초음파 판독결 과 비정상(Abnomal) 이지만 혈액검사 결과 정상 (Nomal)으로 나타난 비율은 AST 35.8\%, ALT 29.8\%, TC $20.9 \%$, GGT $38.5 \%$, TG $37.1 \%$ 로 나타나 초음파 검 사와 임상화학적 검사의 진단 정확도와 부정확도는 각각 $60.8 \%, 39.2 \%$ 로 나타났다. 따라서 지방간 의심소 견을 가진 환자를 진단함에 있어 초음파 검사나 임상 화학적 검사 중 어느 한가지의 검사 결과만으로 확진 하는 것보다 양방향의 검사를 동시에 실시하여 진단 하는 것이 바람직 할 것으로 사료된다.

본 연구를 진행하면서 몇 가지 제안을 해보자면 지 방간은 비만인 환자와 관련이 있다는 연구결과 ${ }^{[7]}$ 가 제 시되어 있으므로 향후 비만인 환자의 혈액검사와 지 방간의 상관성에 관한 추후의 연구가 수행되어야 할 것으로 생각되며, 지방간 또한 알콜성 지방간과 비알 콜성지방간으로 분류된다는 점 ${ }^{[13]}$ 을 밝힌 연구가 선행 되었다는 점을 고려하면 알콜성 지방간과 비알콜성 지방간의 초음파 검사에서의 영상학적 분류에 대한 연구가 심도있게 다루어져야 할 것으로 사료된다. 또 한 초음파 검사시 종사자의 주관적 능력이 병변의 진 단에 큰 영향을 미치는 것으로 알려지고 있어 앞으로 영상의학과 전문의 혹은 방사선사는 초음파 검사 수 행능력을 향상해야 할 것으로 생각된다. 


\section{참 고 문 헌}

[1] 전경녀, 김건우, 김경호, 염헌규, 김태헌. 초음파상의 미만성 지방간과 검사실 소견의 연관성. 대한초음파의학회지 pp.5-9, 1997.

[2] Sexton CC, Zeman RK. Correlation of computed tomography and gross anatomy of liver. AJR No. 141, pp.711-718, 1983.

[3] Hoyumpa AM Jr, Greene HI, Dunn GD, Schenker S, Fatty liver Biochemical and clinical consideration. Digestive Disease. Vol. 20, pp.1142, 1975.

[4] Schiff E, Schiff ER. Disease of liver. 7th ed. Philadelphia, JB Lippincott, pp.825-855, 1993.

[5] Lombardi B. Fatty liver consideration on pathogenesis of fatty liver, Vol. 15, pp.1-6, 1966.

[6] Alder M, Shaffner F. Fatty hepatitis and cirrhosis in obese. Am J Med No. 67, pp.811, 1979.

[7] Bode JC, Kruse G, Mexas P, Martini GA. Alcohol fatty liver, alcohol hepatitis, and alcohol cirrhosis. Dtach Med Wschr No. 109, pp. 1516, 1984.

[8] 문성수, 박찬일. 간 지방 변성에 있어서 말단 간세정맥 주변 섬유화의 정도와 그 의의에 관한 연구.

대한소화기병학회잡지 Vol. 19, No. 2, pp.533- 541, 1987.

[9] Harrisons. Principle of internal medicine, Vol. 12, pp.1352-1355, 1991.

[10] 윤정환, 임대순, 전재윤, 강진경, 최홍재. 생검으로 확진된 지방간의 임상적 고찰. 대한소화기병학회잡지 Vol. 18, No 1 pp.197-204, 1986.

[11] 이진성. 미만성 지방간의 초음파 소견 CT 및 간기능 검사 소견과의 연관. 대한초음파의학회지 No, 13, pp.87-91, 1994.

[12] 박헌진, 안정기, 강원권, 이헌영, 김영건, 이복희, 지방간의 임상적 고찰, 대한소화기병학회잡지, Vol. 21 , No. 1 pp.96-103, 1989.

[13] 정의경, 강영한, 박재용, 남성 건강검진 수진자들에서 알코올성 및 비알코올성 지방간과 대사증후군과의 관련성, 한국콘텐츠학회논문지, Vol. 9, No. 6, pp.237-246, 2009. 